\title{
Maria Tomarchio (éd.), Lo sperimentalismo pedagogico in Sicilia e Michele Crimi
}

Roma, Anicia Editori, 2008, 359 p.

\section{Michel Ostenc}

\section{(2) OpenEdition}

\section{Journals}

Édition électronique

URL : http://journals.openedition.org/assr/22956

DOI : $10.4000 /$ assr.22956

ISSN : $1777-5825$

Éditeur

Éditions de l'EHESS

Édition imprimée

Date de publication : 31 décembre 2011

Pagination : 284

ISBN : 9782713223273

ISSN : 0335-5985

\section{Référence électronique}

Michel Ostenc, «Maria Tomarchio (éd.), Lo sperimentalismo pedagogico in Sicilia e Michele Crimi », Archives de sciences sociales des religions [En ligne], 156 | octobre-décembre 2011, document 156-109, mis en ligne le 17 février 2012, consulté le 21 septembre 2020. URL : http://journals.openedition.org/ assr/22956 ; DOI : https://doi.org/10.4000/assr.22956

Ce document a été généré automatiquement le 21 septembre 2020.

(c) Archives de sciences sociales des religions 


\title{
Maria Tomarchio (éd.), Lo sperimentalismo pedagogico in Sicilia e Michele Crimi
}

Roma, Anicia Editori, 2008, 359 p.

\author{
Michel Ostenc
}

\section{RÉFÉRENCE}

Maria TomARchio (éd.), Lo sperimentalismo pedagogico in Sicilia e Michele Crimi, Roma, Anicia Editori, 2008, 359 p.

1 L'analphabétisme touchait encore plus de $70 \%$ de la population de la Sicile en 1901 contre $56 \%$ pour l'ensemble de l'Italie ; mais des efforts considérables le firent reculer à 58 \% en 1911 alors qu'il atteignait plus de $46 \%$ sur le plan national. L'analphabétisme était considéré comme un fléau dans le Midi italien et dans les îles, et la lutte engagée contre lui suscita de nombreuses vocations. Le pédagogue sicilien Michele Crimi figurait parmi les personnalités les plus engagées dans ce combat avec une âme d'apôtre. Instituteur à Trapani, de 1896 à 1909, il abordait l'enseignement sous ses aspects pratiques et manifestait un intérêt particulier pour l'expérimentation didactique. Sa conception de l'éducation impliquait un engagement social et il collabora pendant des années avec l'association milanaise "Unione femminile » fondée par la poétesse Ada Negri. Michele Crimi échangea par ailleurs une correspondance suivie avec Ersilia Majno Bronzini, une importante figure du mouvement d'émancipation des femmes en Italie au début du xx ${ }^{\mathrm{e}}$ siècle. Il dénonça l'exploitation du travail des enfants dans les latifundias siciliennes et souhaitait les protéger en les plaçant sous la tutelle de l'État.

2 L'instituteur sicilien fit des études supérieures de philosophie à l'université de Naples au moment où la pensée italienne évoluait du positivisme vers un néo-kantisme dont l'éthique devait fournir des éléments concrets à la formation civique et morale des 
jeunes générations. L'ouvrage dirigé par Maria Tomarchio montre clairement les liens unissant Michele Crimi au pédagogue Giuseppe Lombardo-Radice. Pour eux, la laïcité de l'école ne s'identifiait pas à un laïcisme, et ils considéraient la valeur éducative de la religion comme un premier pas vers la conquête d'une vérité rationnelle dans la mesure où elle donnait à l'homme la conscience de la présence de Dieu dans la vie de l'esprit; mais l'enseignement secondaire devait éduquer l'esprit en tant que raison et non pas comme sentiment religieux. Ainsi se concevait cette religiosité plus haute qui constituait l'élément divin de la pensée. Cette conception était celle du néo-idéalisme italien du philosophe Giovanni Gentile; mais pour un praticien de l'école comme Michele Crimi, toute morale ou toute méthode de pensée posait d'abord un problème pédagogique. Le législateur concevait la formation des maîtres comme une incitation à la didactique doublée d'une préparation d'éducateur social. Cette formation magistrale ne convenait guère à Michele Crimi qui concevait l'activité pédagogique comme une vocation découlant d'une synthèse entre les capacités personnelles et les acquis de la formation.

Directeur du gymnase de Marsala (établissement secondaire de premier cycle), Michele Crimi multiplia les institutions parascolaires et il créa en 1912 «L'Educatorio Ricreativo Garibaldi » où les enfants étaient occupés à des travaux de jardinage en dehors des heures de classe. Ces activités pratiques s'inspiraient de l'exemple de la "Scuola della Montesca», une école nouvelle fondée en Ombrie par Alice Franchetti. «L'Educatorio Ricreativo Garibaldi» se distinguait des autres établissements récréatifs italiens de l'époque, à buts essentiellement patriotiques, par son Cours populaire en deux ans qui prolongeait l'école primaire avec un apprentissage du travail manuel. Le pédagogue sicilien animait également les sections locales des sociétés «Pro Infantia » et «Pro Schola ", portant une attention particulière aux laboratoires scientifiques, aux bibliothèques itinérantes et aux colonies de vacances; mais ce sont les écoles de plein air qui illustraient le mieux ses conceptions éducatives. Il eut l'occasion de les exposer au IIIe congrès de la Ligue internationale pour l'Éducation nouvelle à Heidelberg en 1925. Son intervention montra toutefois qu'elles étaient plus éloignées de celles d'Adolphe Ferrière que de l'apostolat de Lombardo-Radice. Ce dernier, promu Directeur de l'Enseignement primaire et populaire par le ministre Gentile, le nomma d'ailleurs inspecteur scolaire à Trapani (1923); mais les démêlés de Michele Crimi avec les autorités fascistes entraînèrent sa mutation dans les Abruzzes où il acheva sa carrière en 1939.

4 L'itinéraire de Michele Crimi est révélateur de l'évolution de la pédagogie italienne au début du $\mathrm{xx}^{\mathrm{e}}$ siècle vers les spéculations dynamiques d'une éducation plus soucieuse de formation civique et morale que de rationalité positive, le cas de Maria Montessori étant tout-à-fait atypique. Cette éthique exigeait une école rénovée qui privilégiait l'initiative de l'élève sur l'acquisition passive des connaissances et assimilait son développement physique et mental à son émancipation intellectuelle et sociale. Ce souci d'adhésion au plus près de la vie réelle se traduisait par un intérêt particulier pour l'apprentissage des métiers manuels et par une profonde défiance à l'égard des techniques pédagogiques figées dans leurs automatismes didactiques; mais il incitait aussi à considérer l'éducateur comme un artiste imbu d'une foi inébranlable dans sa mission plus que comme un professionnel rompu aux pra-tiques de son métier. Les initiatives pédagogiques se situaient dans un cadre restreint fortement impliqué dans la région et la démarche expérimentale sollicitait la sensibilité et la créativité de l'enfant avec une connaissance empirique de sa psychologie. Michele Crimi était 
persuadé de l'existence chez l'enfant des éléments mentaux essentiels à son développement. Les études de Piaget démontreront plus tard que cette conception héritée de Pestalozzi était en partie erronée. L'idéalisme de Michele Crimi refusait de soumettre l'acquisition des connaissances à une logique positiviste; mais il s'avérait plus pragmatique que la philosophie de l'éducation de Giovanni Gentile et il s'apparentait à l'« école sereine » de Lombardo-Radice plus qu'aux « écoles nouvelles » de Ferrière. 